\title{
Diagnosis of Acute Pulmonary Embolism by Endobronchial Ultrasound as an Incidental Finding
}

\author{
J. Sanz-Santos ${ }^{a-c}$ F. Andreo ${ }^{a-d} \quad$ I. García-Olivéa J. Remón ${ }^{b} \quad$ E. Monsó ${ }^{a-d}$ \\ ${ }^{a}$ Servei de Pneumologia, Hospital Universitari Germans Trias i Pujol, Badalona, ${ }^{b}$ Servei de Oncologia, \\ Hospital de Mataró, 'Departament de Medicina, Universitat Antònoma de Barcelona, Barcelona, \\ ${ }^{\mathrm{d}}$ Ciber de Enfermedades Respiratorias (CiBeRes), Bunyol, España
}

A 64-year-old male smoker visited his general practitioner complaining of persistent cough. A chest radiograph showed a mass in the left lower lobe. A computed tomography (CT) scan confirmed the finding and also showed mediastinal nodal enlargement. After the CT scan, the patient suffered a rash and dyspnoea, which were assumed to be the result of allergy to the iodinecontaining contrast medium. Fibreoptic bronchoscopy

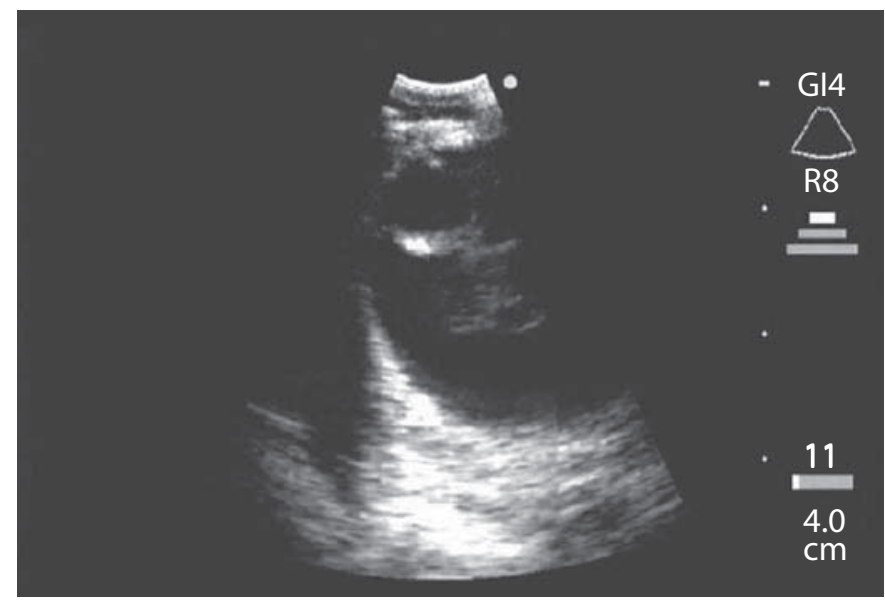

Fig. 1. Appearance of the thrombus in left pulmonary artery by EBUS.

\section{KARGER}

Fax +4161306 1234

E-Mail karger@karger.ch

www.karger.com
C 2010 S. Karger AG, Basel

$0025-7931 / 11 / 0812-0150 \$ 38.00 / 0$

Accessible online at:

www.karger.com/res detected a tumour obstructing the apical segmental bronchus of the left lower lobe. The tumour was biopsied and identified as undifferentiated large cell carcinoma. The patient was referred to the regional hospital for scheduling of endobronchial ultrasound with real-time transbronchial needle aspiration (EBUS-rt-TBNA) for staging.

The following week, the patient suffered a brief syncopal episode. He was seen at the emergency department of

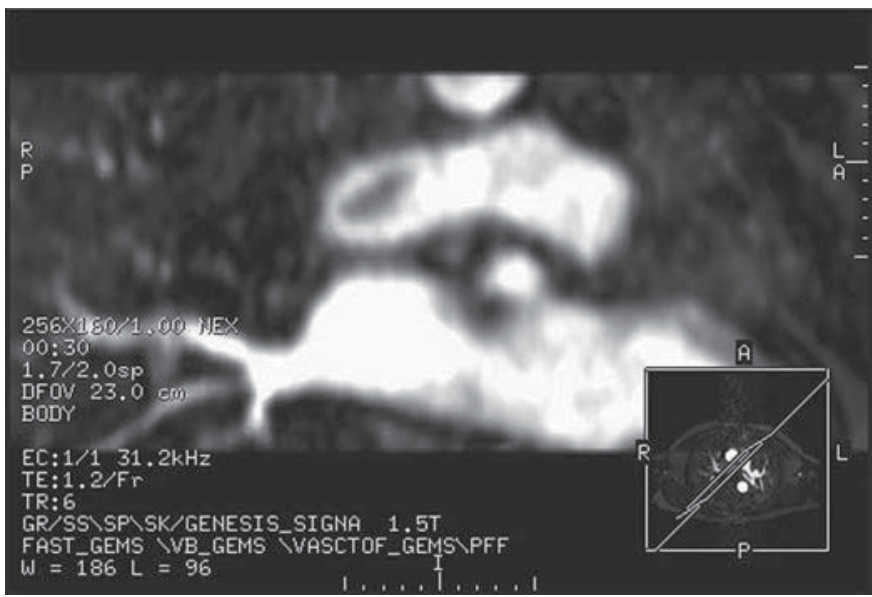

Fig. 2. Thrombus in right pulmonary artery on pulmonary magnetic resonance angiography.

Dr. José Sanz-Santos

Carretera del Canyet $\mathrm{s} / \mathrm{n}$

ES-08916 Badalona (España)

Tel. +34 61520 4087, Fax +3493 4978843

E-Mail 34057jss@comb.cat 
his local hospital and fully recovered. Blood tests, electrocardiogram and a cranial CT scan were carried out at that time; a right zygomatic arch fracture was identified. No additional CT scans or nuclear scintigraphs were performed.

Two days later, EBUS demonstrated two hyperechoic areas inside both pulmonary arteries (fig. 1; online suppl.

Video video 1, www.karger.com/doi/10.1159/000319700). Acute pulmonary embolism was suspected and TBNA was adjourned. Pulmonary magnetic resonance angiography confirmed a thrombus in both pulmonary arteries (fig. 2).
Lung cancer is a well-know risk factor for pulmonary embolism. When EBUS-rt-TBNA is used for staging of lung cancer, great vessels should also be examined for the presence of thrombi.

Reference

1 Aumiller J, Herth FJ, Krasnik M, Eberhadt R: Endobronchial ultrasound for detecting central pulmonary emboli: a pilot study. Respiration 2009;71:298-302. 